\title{
Validation of a Reduced-Order Jet Model for Subsonic and Underexpanded Hydrogen Jets
}

\author{
Xuefang Li ${ }^{\mathrm{a}}$, Ethan S. Hecht ${ }^{\mathrm{b}}$, David M. Christopher ${ }^{\mathrm{a},{ }^{*}}$ \\ ${ }^{a}$ Key Laboratory for Thermal Science and Power Engineering of Ministry of Education, Thermal \\ Engineering Department, Tsinghua University, Beijing 100084 China \\ ${ }^{\text {bS} S a n d i a ~ N a t i o n a l ~ L a b o r a t o r i e s, ~} 7011$ East Avenue, Bldg. 905, Livermore, CA 94551-0969, USA \\ *Corresponding author: David M. Christopher, dmc@tsinghua.edu.cn
}

\begin{abstract}
Much effort has been made to model hydrogen releases from leaks during potential failures of hydrogen storage systems. A reduced-order jet model can be used to quickly characterize these flows, with low computational cost. Notional nozzle models are often used to avoid modeling the complex shock structures produced by the underexpanded jets by determining an "effective" source to produce the observed downstream trends. In this work, the mean hydrogen concentration fields were measured in a series of subsonic and underexpanded jets using a planar laser Rayleigh scattering system. The experimental data was compared to a reduced order jet model for subsonic flows and a notional nozzle model coupled to the jet model for underexpanded jets. The values of some key model parameters were determined by comparisons with the experimental data. The coupled model was also validated against hydrogen concentrations measurements for 100 and 200 bar hydrogen jets with the predictions agreeing well with data in the literature.
\end{abstract}

Keywords: Hydrogen jets, reduced-order jet model, notional nozzle, underexpanded jets

\section{Introduction}

Hydrogen is a promising alternative energy carrier for vehicles to reduce and eventually replace fossil fuels to improve the air quality in modern mega cities and reduce carbon emissions. A growing number of hydrogen fueled vehicles are being developed in many countries, along with the necessary infrastructure, such as hydrogen refueling stations. However, a set of reliable codes and standards is necessary for safe utilization of this fuel that is commonly perceived to be very hazardous. Molkov [1] summarized the state-of-the-art of hydrogen safety studies to demonstrate that hydrogen could be a safer fuel than some traditional fuels such as gasoline because of hydrogen's low density and large diffusivity. Still, there are many knowledge gaps that need to be filled to enhance the technical basis for hydrogen safety engineering.

Leaks from pressurized hydrogen sources will result in a gas jet mixed with the ambient air, which has the potential to be ignited or even self-ignite [1]. Knowledge of the hydrogen dispersion in the atmosphere during an unintended release is critical for calculating the risks inherent in facility 
designs such as hydrogen fueling stations [2]. Hydrogen can leak from a low pressure source, generating a buoyantly driven plume, but typical leaks are underexpanded jets because the flow leaving the orifice is choked. Only when the pressure ratio across the leak orifice is below a critical pressure ratio ( $\approx 1.9$ for hydrogen) would the exiting gas flow have a subsonic velocity and atmospheric pressure. Underexpanded leaks, on the other hand, produce a sonic choked flow at the exit, and the pressure remains higher than the atmospheric pressure until downstream of a complex series of shocks, including a Mach disk [3]. Eventually, after the gas pressure returns to atmospheric pressure, similar dispersion characteristics (i.e. centerline velocity decay rate, Gaussian shaped velocity profiles) as a buoyant jet from a low pressure leak are observed.

The centerline velocities and concentrations of subsonic buoyant jets obey canonical hyperbolic decay laws as has been verified by many experimental studies [4-13]. Most experimental studies have only characterized low pressure leaks with small Froude numbers, with only a few studies focused on underexpanded hydrogen jets $[11,12,14]$. An reduced-order model for turbulent buoyant jets [15], which has been widely used for low pressure leaks to predict flow fields and pollutant distributions, has been employed by many researchers to model subsonic hydrogen jets [4,16-18]. The reduced-order model cannot be directly applied to model high pressure leaks because of the near field complex shock wave region in the underexpanded jets. Computational fluid dynamics (CFD) simulations have been used to predict the flow field of high pressure underexpanded hydrogen jets [14,19-23]; however, the shock region and the hydrogen properties require an extremely fine mesh and low Courant number, making numerical calculations very unstable and slow.

A notional nozzle model can be used to provide effective boundary conditions for a reduced-order model, which reduces a 3-dimensional jet (with curvature due to buoyancy and/or wind) to a single dimension along the streamline. Houf and Winters [24] used real hydrogen properties to calculate a pseudo "Mach disk" to provide boundary conditions for a reduced-order model for a liquid hydrogen leak. Their method [17] was designed for both gas and liquid hydrogen releases. Xiao et al. [25] combined the reduced-order model and a discharge model to simulate transient releases. However, most of these models have used empirical parameters, such as the jet velocity to concentration spreading ratio, from experimental studies $[10,15]$ of subsonic buoyant jets of water or air. The outputs of these coupled notional nozzle and reduced-order models are most often compared only to the centerline concentration decay rates, even though some of the parameters (e.g., the jet velocity to concentration spreading ratio), can strongly affect the concentration half-width. In the present work, the mean concentration fields of a series of subsonic and underexpanded hydrogen jets and one subsonic helium jet were measured using a planar laser Rayleigh scattering (PLRS) diagnostic system. The entire two-dimensional mean concentration fields (cut through the jet axis) were then used to refine several key parameters in a coupled notional nozzle (when needed) and reduced-order model to more accurately predict the concentration fields. The radial spreading rates have a significant effect on the parameters that cannot be seen by using just the centerline decay profiles. The models are then further validated by comparisons to other high pressure experimental data in the literature. 


\section{Experimental}

\subsection{Experiment setup and flow conditions}

The gas concentrations during subsonic releases of hydrogen and helium were measured to validate a reduced-order model (described in Section 3) for subsonic jets. The gas for the subsonic tests was released through a vertical tube having an inside diameter of $1.91 \mathrm{~mm}$. This tube was located in the center of a $63.5 \mathrm{~mm}$ diameter tube with a honeycomb exit plate, where a small (100 SLPM) flow of air helped negate the effects of any room air currents [5]. Hydrogen and helium were used as test gases. The experimental conditions for the subsonic jets are listed in Table 1. The flow rates were selected to create momentum dominated jets with the Froude number defined as:

$$
F r=\frac{u_{\text {exit }}}{\sqrt{g d_{\text {exit }} \frac{\rho_{\infty}-\rho_{\text {exit }}}{\rho_{\text {exit }}}}}
$$

where $u$ is the velocity (plug flow assumed), $\rho$ is the density, $d$ is the diameter, $g$ is the acceleration due to gravity and the subscript exit denotes the nozzle exit. The Reynolds number was calculated as $\operatorname{Re}=u_{\text {exit }} d_{\text {exit }} / v$, where $v$ is the kinematic viscosity of the gas. The Froude numbers used in the subsonic jet experiments were in the range of 10 to 1000, which means that the jets were influenced by both the initial momentum of the release and by buoyancy [5]. However, since the Froude numbers were relatively large for these vertical flows, the momentum effects dominate over the buoyancy effects.

In separate experiments, high-pressure releases were studied using the apparatus described in detail by Ruggles and Ekoto [11]. Briefly, a custom designed high-pressure stagnation chamber with an internal volume of $1.24 \mathrm{~L}$ was used to create underexpanded hydrogen jets with static pressures $\left(P_{0}\right)$ up to 60 bar. A set of interchangeable nozzles with diameters ranging from $0.5 \mathrm{~mm}$ to $1.5 \mathrm{~mm}$ were attached to the stagnation chamber to give data for different flow scales. Long radius nozzle profiles based on the ASME MFC-3M-2004 standard were used to produce nearly uniform exit velocity profiles. The gas stagnation temperature was monitored by a type $\mathrm{K}$ thermocouple, while the chamber pressure was measured by a TESCOM series 100 pressure transducer. The stagnation pressure inside the chamber was controlled by a dynamic feedback loop [11]. Tests were run with a series of underexpanded hydrogen jets at various pressure ratios using different nozzles. The experimental conditions are summarized in Table 2.

The downstream gas concentrations in the subsonic and high-pressure releases were quantified using a Planar Laser Rayleigh Scattering (PLRS) system. The PLRS setup was similar to that described by Ruggles and Ekoto [11]. Briefly, a Nd:YAG laser (frequency doubled to $532 \mathrm{~nm}$, with $\approx 9 \mathrm{~ns}$ pulse duration, $1 \mathrm{~J} /$ pulse) was formed into a sheet approximately $40 \mathrm{~mm}$ high. During the experiments, the large spreading area of the hydrogen jet necessitated two cameras placed perpendicular to the laser sheet. A Princeton Instruments PI-MAX intensified camera with a f1.4 Nikon $50 \mathrm{~mm}$ lens mounted on $12 \mathrm{~mm}$ extension was used to image a region with pure air to 
determine the laser sheet profile. Before the under-expanded jet experiments, a correction for the non-linear gain and flat-field response of the PI-MAX camera was generated using the method described by Williams and Shaddix [26]. A Princeton Instruments PIXIS 400B camera with an $f 1.2$ Nikon $50 \mathrm{~mm}$ lens and a Nikon 3T close up lens was used to image the jet region. The obtained intensity images were then turned into mole fractions by subtracting the background images and normalizing by the optical response of the camera [11,27]. The ideal gas law was assumed to convert these mole fractions to mass fraction. The jet was traversed vertically in 30 $\mathrm{mm}$ increments (the height of high-power section of the laser sheet), with 3 to 5 regions imaged for each condition to give an overall field of view of 100 to $160 \mathrm{~mm}$. To avoid temperature induced errors in the species field measurements, a thermocouple was used to measure the jet temperature along the jet centerline to determine the position where the jet temperature returned to within $2^{\circ} \mathrm{C}$ of ambient for each case. The PLRS measurements began at this position, after the thermocouple was removed from the flow stream. The nearly instantaneous species fields were averaged over 798 measurements taken at 2 measurements per second to determine the mean species fields. All the pressure ratios in this study resulted in choked flow the nozzle exit. The nozzle exit density at each pressure ratio was calculated assuming isentropic flow with the gas at the sonic velocity at the exit. The nozzle exit densities and velocities are also listed in Table 2. During the experiments, the room temperature and pressure were approximately $294 \mathrm{~K}$ and 1 bar.

Table 1 Experimental conditions for the subsonic jets.

\begin{tabular}{cccccc}
\hline Gas & Flow rate $(\mathrm{s} / \mathrm{m})$ & $u_{\text {exit }}(\mathrm{m} / \mathrm{s})$ & $\rho_{\text {exit }}\left(\mathrm{kg} / \mathrm{m}^{3}\right)$ & $\mathrm{Fr}$ & $\mathrm{Re}$ \\
\hline $\mathrm{H}_{2}$ & 45 & 263.1 & 0.0838 & 527.5 & 4774 \\
$\mathrm{He}$ & 50 & 292.4 & 0.1663 & 858.3 & 4721 \\
\hline
\end{tabular}

Table 2 Experimental conditions for the underexpanded jets. The nozzle diameters were $0.5 \mathrm{~mm}$, $0.75 \mathrm{~mm}, 1.0 \mathrm{~mm}, 1.25 \mathrm{~mm}$ and $1.5 \mathrm{~mm}$.

\begin{tabular}{cccc}
\hline Gas & $P_{0}($ bar $)$ & $\rho_{\text {exit }}\left(\mathrm{kg} / \mathrm{m}^{3}\right)$ & $u_{\text {exit }}(\mathrm{m} / \mathrm{s})$ \\
\hline $\mathrm{H}_{2}$ & 10 & 0.52 & 1196.3 \\
$\mathrm{H}_{2}$ & 30 & 1.55 & 1205.1 \\
$\mathrm{H}_{2}$ & 50 & 2.60 & 1213.9 \\
$\mathrm{H}_{2}$ & 60 & 3.06 & 1218.3 \\
\hline
\end{tabular}

\subsection{Experimental results}

The centerline mass fractions in the subsonic jets are shown in Figure 1. The data for both jets collapses onto a single straight line when the axial distance, $z$, is normalized by the characteristic jet exit diameter, $d^{*}=d_{\text {exit }}\left(\rho_{\text {exit }} / \rho_{\infty}\right)^{0.5}$ [28]. The mass fraction decay rate along the jet centerline is 0.2 , which is in good agreement with previously reported values $[5,6]$ for Froude numbers less than 1000 . The centerline mass fraction decay for non-reacting jets is usually correlated with the distance from a virtual origin resulting in a linear equation with a non-zero intercept $[5,13,29]$. However, the current experimental data shows that a virtual origin is not necessary for this Froude number range, since the linear correlation with a zero intercept in 
Figure 1 fits the data well with an R squared correlation coefficient $\left(R^{2}\right)$ of 0.994 . The linear relationship between the inverse of the mass fraction and the normalized axial distance also verifies that both jets are in the momentum dominated regime.

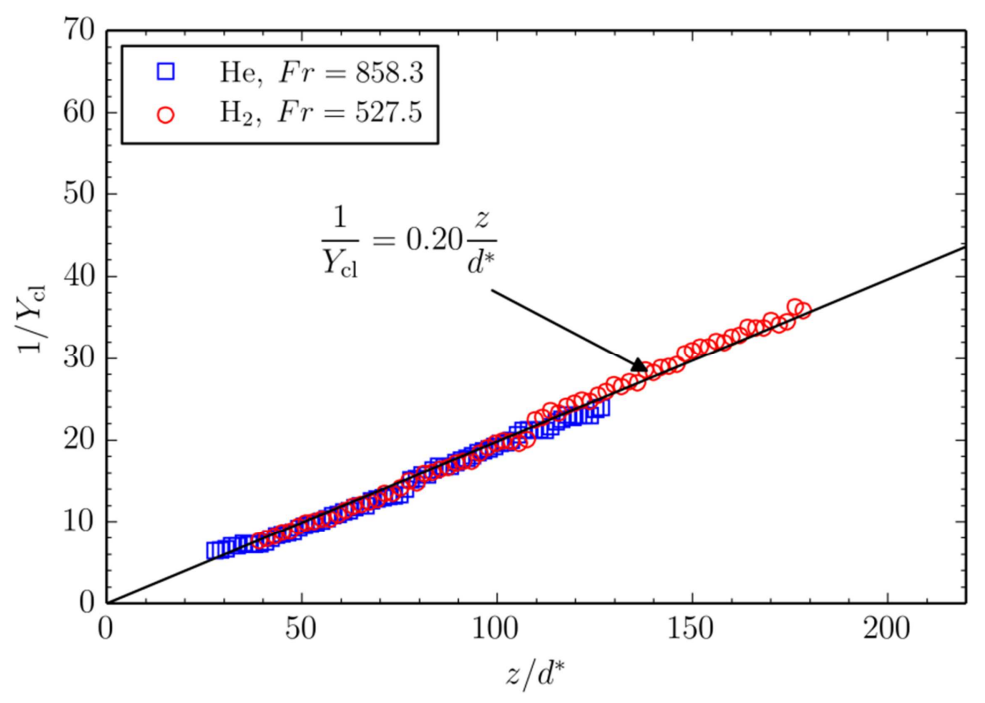

Figure 1 Centerline mass fraction decay profiles in the subsonic jets.

The centerline values of the inverse of the hydrogen mass fraction of the underexpanded jets are shown in Figure 2. The data for the $0.5 \mathrm{~mm}$ nozzle are not included because Schlieren images showed that the gas left the nozzle at an angle from vertical, pushing the centerline off of the vertical axis. In Figure 2, the axial distance is again normalized by the characteristic jet exit diameter. The decay rate (0.26) is greater than for the subsonic jet measurements, but agrees with Richards and Pitts [29]. Ruggles and Ekoto [11] also observed a higher decay rate (0.22) in experimental data for an underexpanded jet with a pressure ratio of 10:1. The high exit velocities of the underexpanded jets resulted in much higher Froude numbers $(8,618$ to 36,458$)$ than for the subsonic jets with a virtual origin of -3.6 needed in the correlation in Figure 2.

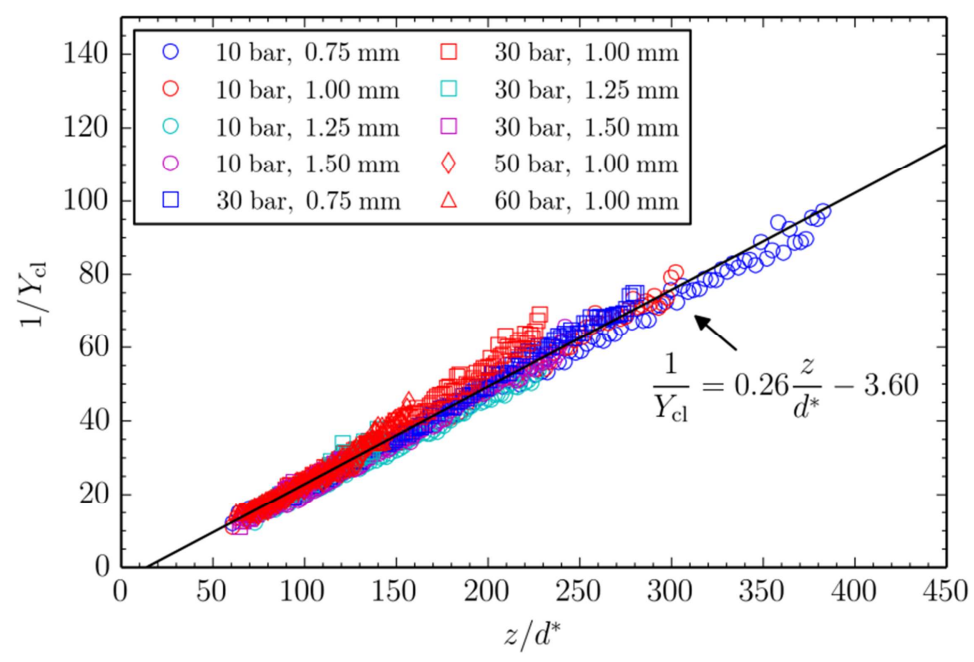

Figure 2 Centerline mass fraction decay in the underexpanded jets. 


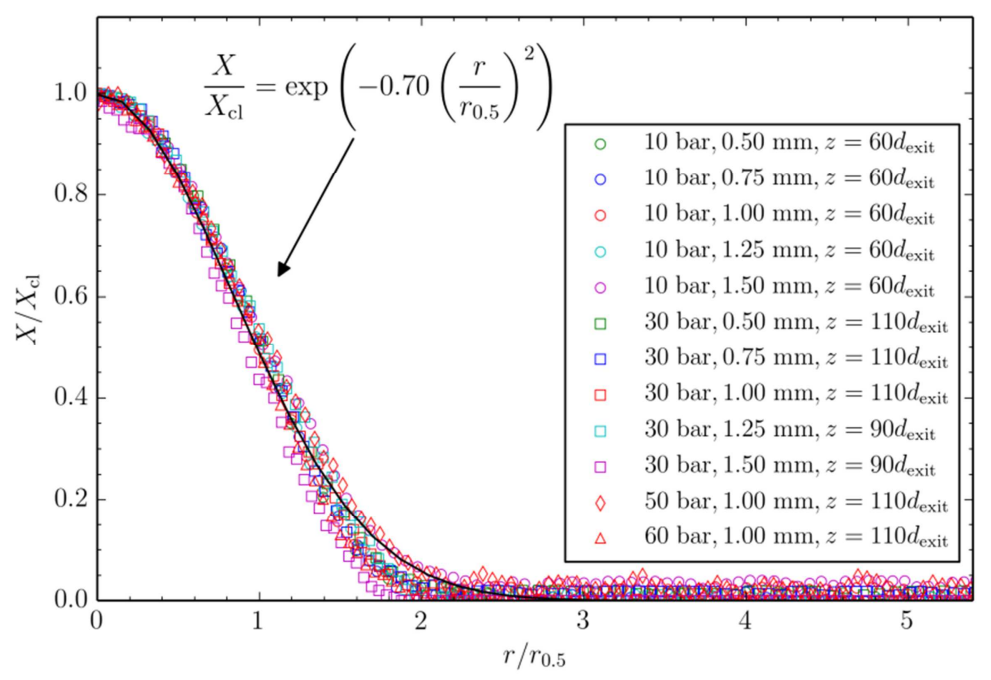

Figure 3 Normalized radial mole fraction profiles for the underexpanded jets.

The normalized radial concentration profiles in the underexpanded jets are shown in Figure 3, with the results for different stagnation pressures marked by different symbols and the results for different nozzle diameters represented by different colors. Only one axial location, $z$, was chosen for each case to limit the number of data points, but the trends hold true for the entire data set. The mole fraction profiles are shown here (rather than the mass fraction), since the concentration spreading is directly proportional to the mole fraction profile. The radial mole fraction, $X$, at each distance from the nozzle was normalized by the jet centerline mole fraction, $X_{\mathrm{cl}}$, at the same axial location. The radial distance was normalized by the mole-fraction half radius, $r_{0.5}$, defined as the radial location at which the mole fraction is equal to half of its centerline value. All the profiles collapse onto a normalized Gaussian curve as shown in Figure 3. This result is consistent with many other experimental studies $[5,29,30]$. The radial concentration profiles of the subsonic jets are similar to those for the underexpanded jets and are not included here.

The variation of the mole-fraction half radius with axial distance is shown in Figure 4. The mole-fraction half radius and the axial distance were both normalized by the nozzle exit diameter. All the data for both the subsonic and the underexpanded jets collapses onto a single line, which reflects that the jet width increases linearly with the axial distance. The slope of the best fit line is the concentration spreading rate, $k_{\mathrm{c}}$, which is a constant. The data in Figure 4 shows that there is a slight difference between the spreading rates of the subsonic jets (red dashed line) and the underexpanded jets (blue dashed line). The best fit of all the data gave $k_{\mathrm{c}}=0.125$ (solid line). The mass fraction spreading rate was also calculated, by fitting the experimental data, to compare with other experimental results. The best-fit mass-fraction spreading rate for all of the subsonic and underexpanded jet data was found to be 0.115. Pitts [13] reviewed all the experimentally determined slopes for the mass-fraction half width relative to the downstream distance and found a range of mass-fraction spreading-rates from 0.088 to 0.125 with most of the values within 0.11 to 0.12 , which is in good agreement with the present study. 


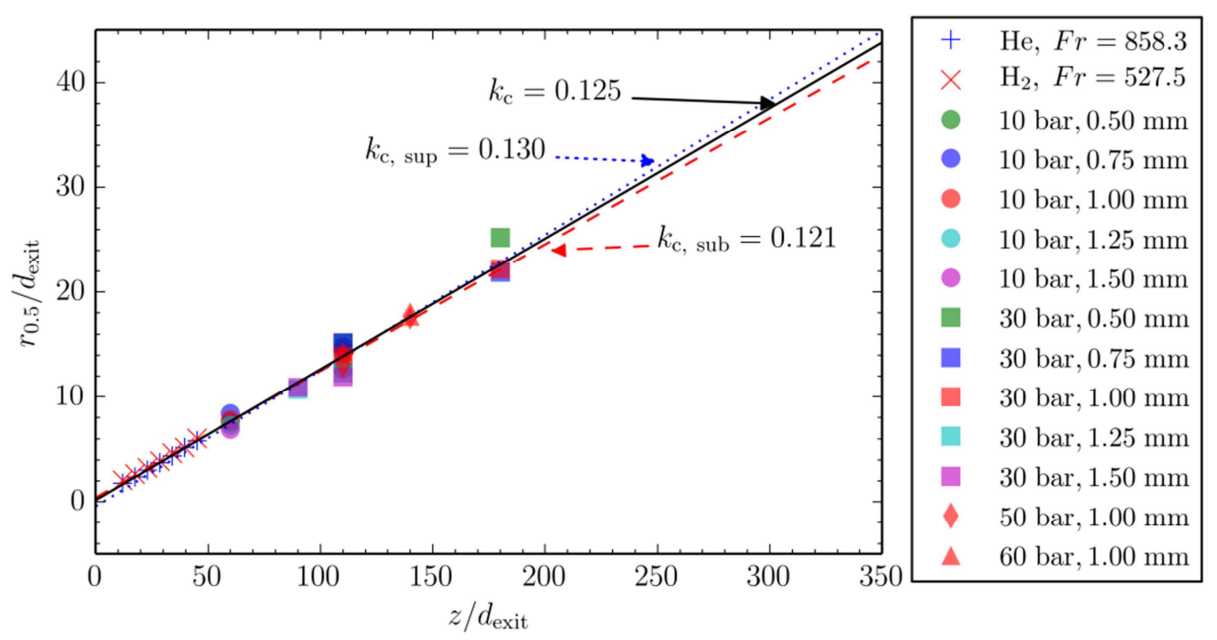

Figure 4 Variation of the mole-fraction half radius with axial distance for subsonic and underexpanded jets. For the underexpanded jets, the different stagnant pressures are distinguished by the different colors while different nozzle diameters are marked by different symbols. The dashed line is the best fit of the mass-fraction half radius for the subsonic jets data, the blue dotted line is for the underexpanded jet data and the solid line is for all of the data. The subscript sub denotes the subsonic jets, while sup denotes the underexpanded jets.

\section{Models}

\subsection{Reduced-order model}

The first-order model described by Houf and Schefer [4] is based on the integral turbulent buoyant jet model [15] which has been widely used to model water discharges as well as turbulent gas jets. The model uses the differential conservation equations for mass, momentum, and species. The integral conservation equations are:

$$
\begin{gathered}
\frac{\partial}{\partial S} \int_{0}^{2 \pi} \int_{0}^{\infty} \rho u r \mathrm{~d} r \mathrm{~d} \phi=\rho_{\infty} E \\
\frac{\partial}{\partial S} \int_{0}^{2 \pi} \int_{0}^{\infty} \rho u^{2} \cos \theta r \mathrm{~d} r \mathrm{~d} \phi=0 \\
\frac{\partial}{\partial S} \int_{0}^{2 \pi} \int_{0}^{\infty} \rho u^{2} \sin \theta r \mathrm{~d} r \mathrm{~d} \phi=\int_{0}^{2 \pi} \int_{0}^{\infty}\left(\rho_{\infty}-\rho\right) g r \mathrm{~d} r \mathrm{~d} \phi \\
\frac{\partial}{\partial S} \int_{0}^{2 \pi} \int_{0}^{\infty} \rho u Y r \mathrm{~d} r \mathrm{~d} \phi=0
\end{gathered}
$$




$$
\begin{gathered}
\frac{\partial}{\partial S}(x)=\cos \theta \\
\frac{\partial}{\partial S}(z)=\sin \theta
\end{gathered}
$$

where $E$ is the air entrainment, $Y$ is the mass fraction of hydrogen in the jet, $x$ and $z$ are the horizontal and vertical coordinates of the jet centerline, $S$ is the streamline coordinate along the jet centerline (also denoted by $z$ for a vertical jet), $r$ is the radial distance from the jet centerline, $\theta$ is the angle between the streamline direction and the horizontal, the $x$-axis, and the subscript $\infty$ denotes the atmospheric, far-field conditions. More details of the model can be found in Houf and Schefer [4] and Winters [17].

The dimensionality is reduced by specifying (as is observed experimentally) that the mean jet velocity and density have Gaussian profiles in the radial direction (normal to the jet centerline), as

$$
\begin{gathered}
u=u_{\mathrm{cl}}(S) \exp \left(-\left(\frac{r}{B}\right)^{2}\right) \\
\rho=\rho_{\infty}-\left(\rho_{\infty}-\rho_{\mathrm{cl}}(S)\right) \exp \left(-\left(\frac{r}{\lambda B}\right)^{2}\right)
\end{gathered}
$$

where $\lambda$ is the relative spreading ratio between the velocity and density fields. $B$ is a characteristic jet width defined at the point on the profile at which the velocity is $1 / e$ times the centerline value. The subscript $\mathrm{cl}$ denotes along the centerline $(r=0)$. The hydrogen mass fraction profile, $Y$, is assumed to be given by

$$
\rho Y=\rho_{\mathrm{cl}} Y_{\mathrm{cl}} \exp \left(-\left(\frac{r}{\lambda B}\right)^{2}\right)
$$

For gas jets, this reduced-order model applies only to expanded buoyant jets, which means that the jets are at the same pressure and temperature as the ambient air and behave as ideal gases. Hence, for a binary gas mixture, the density and mole fraction are related as

$$
Y=\frac{M_{\mathrm{gas}}}{M_{\mathrm{air}}-M_{\mathrm{gas}}}\left(\frac{\rho_{\infty}}{\rho}-1\right)
$$

where $M$ denotes the molecular weights of the air and the gas.

The air entrainment is modeled with a momentum term, which is a function of the jet velocity at the nozzle exit: 


$$
E_{\text {mom }}=\beta_{\mathrm{A}} \sqrt{\frac{\pi D^{2}}{4} \frac{\rho_{\text {exit }} u_{\text {exit }}}{\rho_{\infty}}}
$$

and a buoyancy term, which is a function of the local Froude number:

$$
E_{\text {buoy }}=\frac{a_{2}}{F r_{1}}\left(2 \pi u_{\mathrm{cl}} B\right) \sin \theta
$$

where $\beta_{\mathrm{A}}$ and $a_{2}$ are empirical coefficients and the subscript exit denotes the nozzle exit condition. The local Froude number is defined as

$$
F r_{1}=\frac{u_{\mathrm{cl}}}{\sqrt{g B \frac{\rho_{\infty}-\rho_{\mathrm{cl}}}{\rho_{\mathrm{exit}}}}}
$$

The boundary conditions needed for this model are the jet starting point (i.e. the length of the flow establishment zone), $S_{\mathrm{E}}$, the centerline density, $\rho_{\mathrm{cl}, \mathrm{E}}$, the centerline velocity, $u_{\mathrm{cl}, \mathrm{E}}$, and the characteristic jet width, $B_{\mathrm{E}}$, at the jet starting point. $S_{\mathrm{E}}$ and $B_{\mathrm{E}}$ are related to the nozzle exit diameter as

$$
\begin{aligned}
& S_{\mathrm{E}}=\beta_{\mathrm{S}} d_{\text {exit }} \\
& B_{\mathrm{E}}=\beta_{\mathrm{B}} d_{\text {exit }}
\end{aligned}
$$

where $\beta_{\mathrm{S}}$ and $\beta_{\mathrm{B}}$ are empirical constants and $d_{\text {exit }}$ is the nozzle exit diameter. The mass conservation equation from the nozzle exit to the jet starting point is

$$
\rho_{\text {exit }} u_{\text {exit }} \frac{\pi d_{\text {exit }}^{2}}{4}=2 \pi \int_{0}^{\infty} \rho u Y r d r
$$

Substituting the Gaussian profiles for the velocity and the mass fraction given by Eqs. (8) and (10) into Eq. (17) yields the initial centerline velocity:

$$
u_{\mathrm{cl}, \mathrm{E}}=\frac{\rho_{\mathrm{exit}} d_{\mathrm{exit}}^{2}\left(1+\lambda^{2}\right)}{4 \rho_{\mathrm{cl}, \mathrm{E}} Y_{\mathrm{cl}, \mathrm{E}} \lambda^{2} B_{\mathrm{E}}^{2}} u_{\mathrm{exit}}
$$

where $Y_{\mathrm{cl}, \mathrm{E}}$ is calculated using [17]:

$$
Y_{\mathrm{cl}, \mathrm{E}}=\frac{\lambda^{2}+1}{2 \lambda^{2}}
$$




\subsection{Key parameters}

The reduced-order model described in section 3.1 has several key parameters: $\beta_{\mathrm{S}}$ and $\beta_{\mathrm{B}}$ for the initial conditions and the relative spreading ratio, $\lambda$, that are necessary to complete the model. The air entrainment equations also have two empirical constants, $\beta_{\mathrm{A}}$ and $a_{2}$. Substituting Eq. (14) into Eq. (13) shows that $E_{\text {buoy }}$ is proportional to the inverse of the local centerline velocity, $1 / u_{\mathrm{cl}}$. In the momentum dominated regime, the high centerline velocity results in much less buoyancy induced entrainment than momentum induced entrainment. Hence, $\beta_{\mathrm{A}}$ is a fourth key variable for reproducing the experimental data, while variations in $a_{2}$ have only a minor effect on the results, so $a_{2}$ was assumed to be 0.97 [4].

The ratio of the length of the flow establishment zone to the nozzle exit diameter, $\beta_{\mathrm{S}}$, has historically been assumed to be $6.2 d_{\text {exit }}$ for turbulent jets $\left(\mathrm{Fr}^{2} \geq 40\right)$ with an assumed plug flow velocity profile exiting the nozzle $[17,31]$. However, the Reynolds numbers of the subsonic jets in the present paper were relatively small (both under 5000), which means that the flows exiting the nozzle may not be fully turbulent and the plug flow assumption may not hold true for these cases. Thus, this relationship for $\beta_{S}$ may not be appropriate. The boundary conditions for the model should be specified at the 'virtual' origin, where the mean centerline mass (or mole) fraction is the source value ( 1 for the pure hydrogen in this study), which could in some cases be non-physical (a negative virtual origin). The experimental data shown in Figure 1 suggests that the virtual origin is essentially zero for the subsonic jets $(\mathrm{Fr}<1000)$. The correlation of the centerline concentrations for the underexpanded jets given in Figure 2 gives a virtual origin of $z / d^{*}=3.6$, which is slightly less than $z / d^{*}=4$ given by Schefer et al. [5]. Given these observations, the present work also treats $\beta_{\mathrm{S}}$ as a fit variable.

The characteristic jet width at the end of the flow establishment region, $B_{\mathrm{E}}$, which is related to the jet exit diameter as in Eq. (16), is also needed as a boundary condition for the differential equations. Gebhart et al. [15] set $\beta_{\mathrm{B}}$ to 0.707 based on the analytical model of Hirst [32]. However, the $B_{\mathrm{E}}$ used in both Gebhart et al. [15] and Hirst [32] were used to model hot water discharges and may not be applicable to gas jets that may have different velocity spreading rates. $\beta_{\mathrm{B}}$ used by Winters [17] was calculated from $\lambda$ by solving the conservation equations for mass and momentum from the nozzle exit to the end of the flow establishment region while neglecting the air entrainment in the flow establishment region. In the present work, $\beta_{\mathrm{B}}$ was also specified as a fit parameter to match the model predictions to the measured concentration field data.

For turbulent jets, the mean concentration profile and the mean velocity profile spread at different rates. The relative concentration to velocity spreading ratio, $\lambda$, is another key parameter in this model. Gebhart et al. [15] used a spreading ratio of $\lambda=1.16$ for hot water discharges. Houf and Schefer [4] used this value $(\lambda=1.16)$ to model hydrogen jets. El-Amin and Kanayama [16] used the expression $\lambda=k_{\mathrm{c}} / k_{\mathrm{m}}$ where $k_{\mathrm{c}}$, the concentration spreading rate, and $k_{\mathrm{m}}$, the momentum (velocity) spreading rate, were obtained from the concentration profiles in Schefer et al. [5]. El-Amin and Kanayama [16] found $\lambda=1.2$, which is very close to value in Houf and Schefer [4]. As discussed in Section 4, in the present work, $\lambda$ was determined from a fit to the data, but was constrained. Based on the observations discussed in Section 2.2, and a literature search, $k_{\mathrm{c}}$ was constrained to lie between 0.121 and 0.130 , while $k_{\mathrm{m}}$ was 
constrained to fall within 0.08 and $0.13[30,33-36]$. This results in the bounds on $\lambda$ of 0.96 to 1.55 .

While Houf and Schefer were able to accurately predict the centerline concentrations of their hydrogen jets, they did not compare the measured and predicted radial mole fraction profiles [4]. Figure 5 compares the reduced-order model results to the measured radial profiles for the subsonic hydrogen jet in the present study. Although the centerline concentrations (the peak concentrations on each curve) are in good agreement, the predicted radial profiles are much "skinnier" than the experimental data with the small spreading ratio, $\lambda=1.16$, used by Houf and Schefer [4]. As $\lambda$ increases from 1 to 1.9, the centerline mole fractions shown in Figure 6, $(r$ $=0$, green dots) decrease slightly, while the mole fractions off of the centerline increase by a much greater amount. This highlights the importance of looking at the concentrations in the jet periphery, rather than only the centerline concentrations, to accurately determine the spreading ratio, $\lambda$.

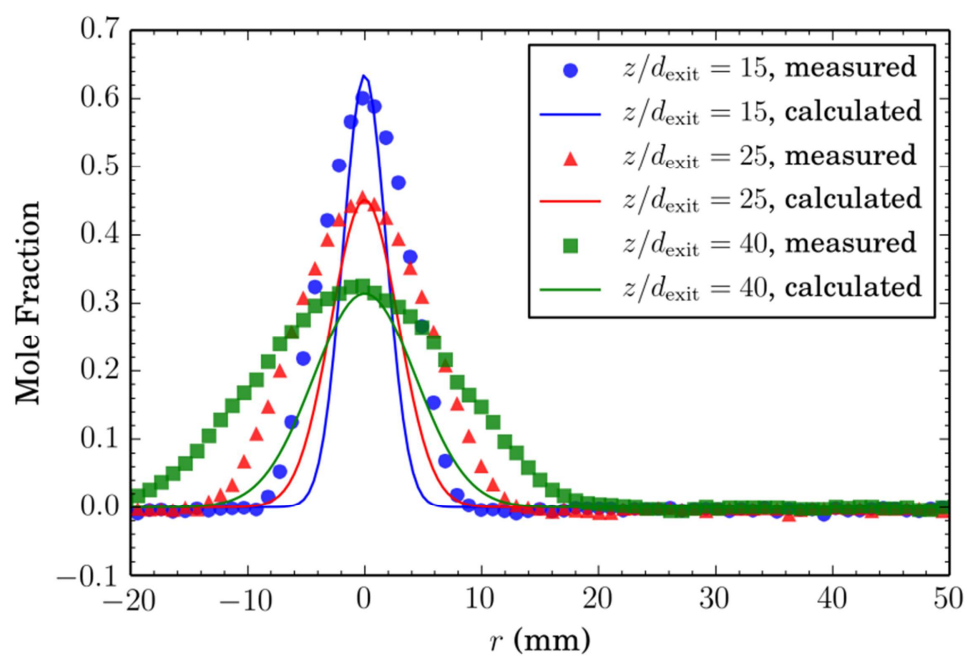

Figure 5 Measured and predicted mean radial mole fractions for a subsonic hydrogen jet with a flow rate of $45 \operatorname{sim}\left(\lambda=1.16, \beta_{\mathrm{A}}=0.282, \beta_{\mathrm{S}}=6.2, \beta_{\mathrm{B}}=0.575,\right)$.

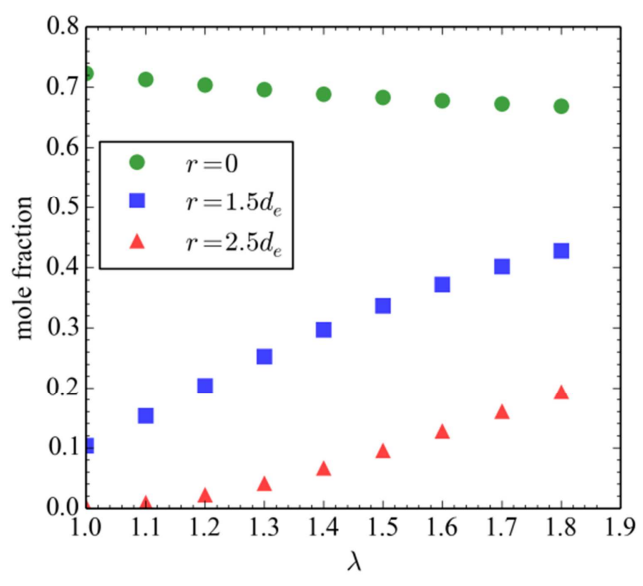

(a) Hydrogen jet, $F r=527.5$

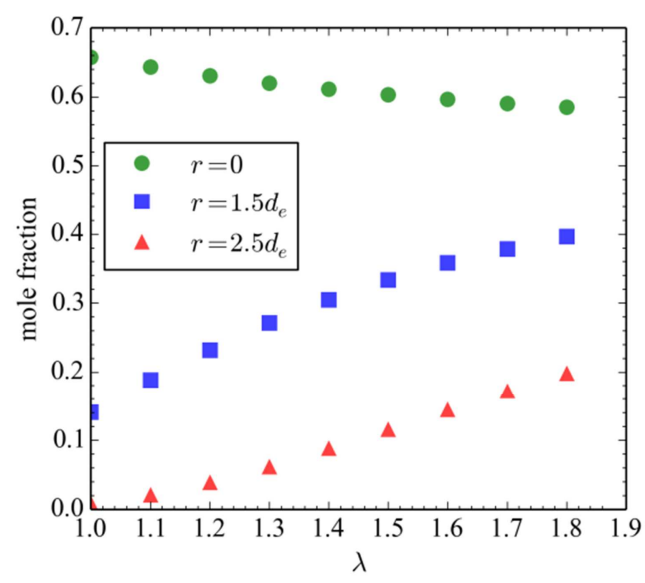

(b) Helium jet, $F r=858.3$

Figure 6 Effect of $\lambda$ on the predicted mole fractions at three radial positions for $\mathrm{d}_{\text {exit }}=1.91 \mathrm{~mm}(z$ $=14 d_{\text {exit }}$ ) 


\subsection{Notional nozzle model}

The actual nozzle exit conditions for the underexpanded jets were calculated by assuming that the hydrogen expands isentropically to the speed of sound. The non-ideal gas equation of state in the Python CoolProp library [37] was used to iteratively solve for the thermodynamic state and the throat (exit) velocity. The jet velocity and thermodynamic conditions at the "effective" exit were then calculated from the notional nozzle model described by Birch [38]. Briefly, the model assumes that the pressure and temperature at the jet exit of the notional nozzle are reduced to ambient conditions after passing through the notional expansion region. The conservation of mass and momentum equations give the effective diameter and velocity at the notional nozzle exit as

$$
\begin{gathered}
d_{\text {eff }}=\frac{\rho_{\text {exit }} u_{\text {exit }} d_{\text {exit }}}{\sqrt{\rho_{\text {gas }}\left(P_{\text {exit }}-P_{\infty}+\rho_{\text {exit }} u_{\text {exit }}^{2}\right)}} \\
u_{\text {eff }}=u_{\text {exit }}+\frac{P_{\text {exit }}-P_{\infty}}{\rho_{\text {exit }} u_{\text {exit }}}
\end{gathered}
$$

where $\rho_{\text {gas }}$ is the hydrogen density at ambient pressure and temperature.

\section{Modeling results and validation}

As described in Section 2, both the subsonic and underexpanded jet measurements (far from the shock region) showed the canonical hyperbolic centerline decay rates and self-similar Gaussian radial profiles for the mean mole fraction that would be expected from a momentum dominated subsonic jet. The model described in Section 3.1 was solved using a program written in Python. An error equation was cast with 4 parameters $\left(\lambda, \beta_{\mathrm{A}}, \beta_{\mathrm{S}}\right.$, and $\left.\beta_{\mathrm{B}}\right)$, where the total error $\varepsilon=\sum_{\mathrm{xz}}$ $\left(X_{\text {measured }}-X_{\text {calculated }}\right)^{2}$ with $X$ as the mean mole fraction at each $x$ and $z$ location. The $S$ and $r$ coordinates from the reduced-order model map directly to $z$ and $x$ for the vertical jets studied here. The error was summed over all the pixels. A differential evolution algorithm [39] and a basin hopping algorithm [40] were used to minimize the error between the measured and calculated mole fraction fields.

The calculated mole fractions agreed best with the measured data with $\lambda=1.510, \beta_{\mathrm{A}}=0.248, \beta_{\mathrm{S}}=$ 0 , and $\beta_{\mathrm{B}}=0.763$ for the subsonic jets. The calculated subsonic hydrogen jet concentration profiles are compared to the experimental data in Figure 7 for a hydrogen release with a Froude number of 527. Figure 7(a) compares the predicted and measured axial mole fraction decay histories with the model slightly underestimating the mole fraction before $28 d_{\text {exit }}$. Figure $7(b)$ shows the predicted and measured radial mole fraction profiles at different axial locations, which shows much better agreement than in Figure 5 with the best-fit parameters. The predicted and measured 0.3 and 0.04 (lean flammability limit, LFL) mole fraction contours are compared in Figure $7(c)$, which shows that the model accurately predicts the experimental data. 


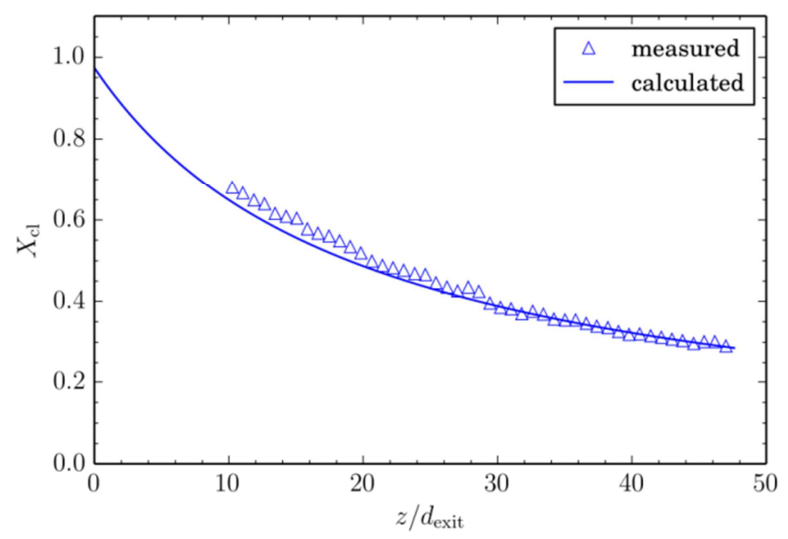

(a) Axial mean mole fraction distribution

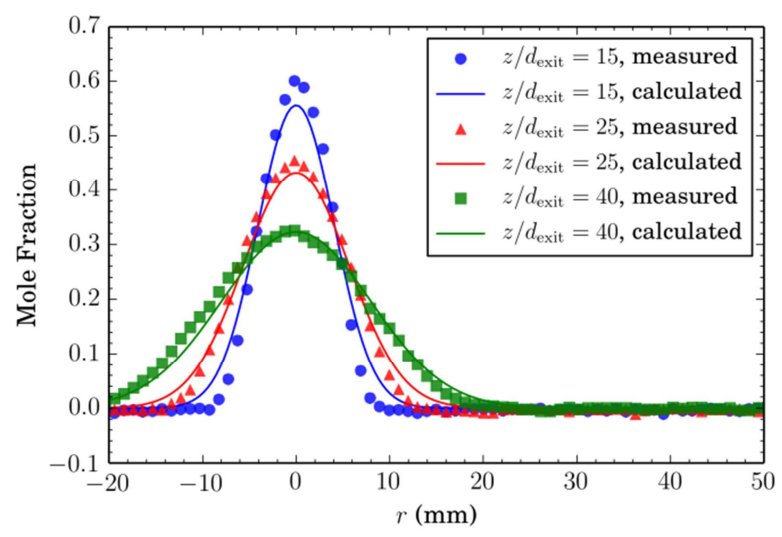

(b) Radial mean mole fraction profiles

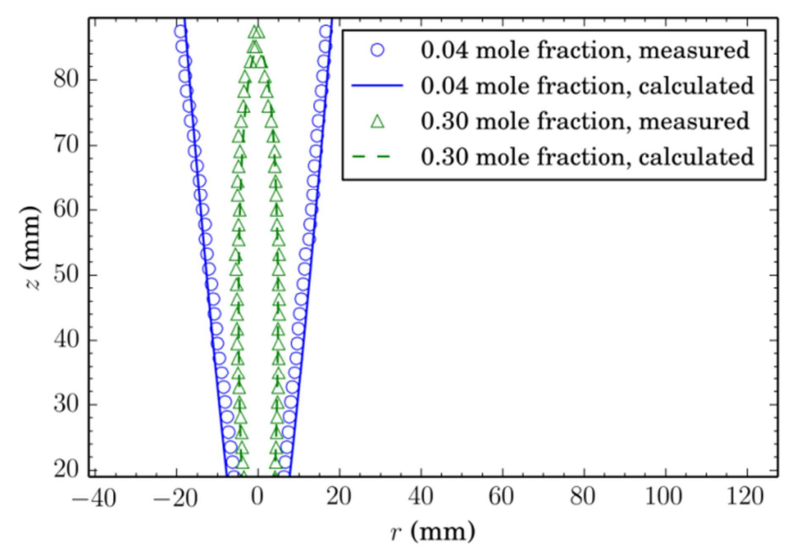

(c) 0.30 and 0.04 mean mole fraction profiles

Figure 7 Measured and predicted mole fraction profiles for the subsonic hydrogen jet with a Froude number of $527.5\left(\lambda=1.510, \beta_{\mathrm{A}}=0.248, \beta_{\mathrm{S}}=0\right.$, and $\left.\beta_{\mathrm{B}}=0.763\right)$.

The model was also applied to the supersonic underexpanded jets using the effective exit conditions calculated by the notional nozzle model described in section 3.3. The same error equation and fitting process were then used to determine the model parameters. The values of the tunable parameters for the underexpanded jets were founded to be very close to those of the subsonic jets except for $\beta_{\mathrm{S}}$, with $\lambda=1.529, \beta_{\mathrm{A}}=0.281, \beta_{\mathrm{S}}=8.632$, and $\beta_{\mathrm{B}}=0.820$. $\beta_{\mathrm{S}}$ is related to the virtual origin location as discussed in Section 2.2. For underexpanded jets, compression of 
the gas in the shock region likely shifts the virtual origin and flow development characteristics. This agrees with Ruggles and Ekoto [11] who note that growth rates are slower for compressible shear layers than for incompressible shear layers, requiring a large virtual origin in an incompressible reduced-order model, as used here. The calculated mole fractions along the jet centerline are compared to the measured data in Figure 8(a) for the $1 \mathrm{~mm}$ nozzle exit diameter. The model accurately reproduced the mole fraction decay rates along the centerline with slight over-predictions for the 30 bar and 60 bar cases. The calculated radial mole fraction distributions are also in good agreement with the experimental data for a stagnation pressure of 10 bar, as shown in Figure 8(b).

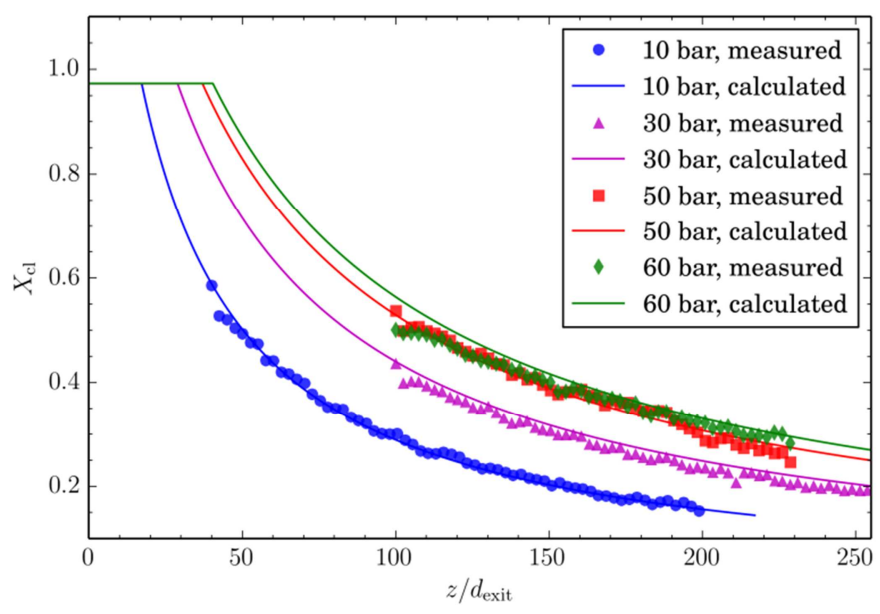

(a) centerline mean mole fraction decay

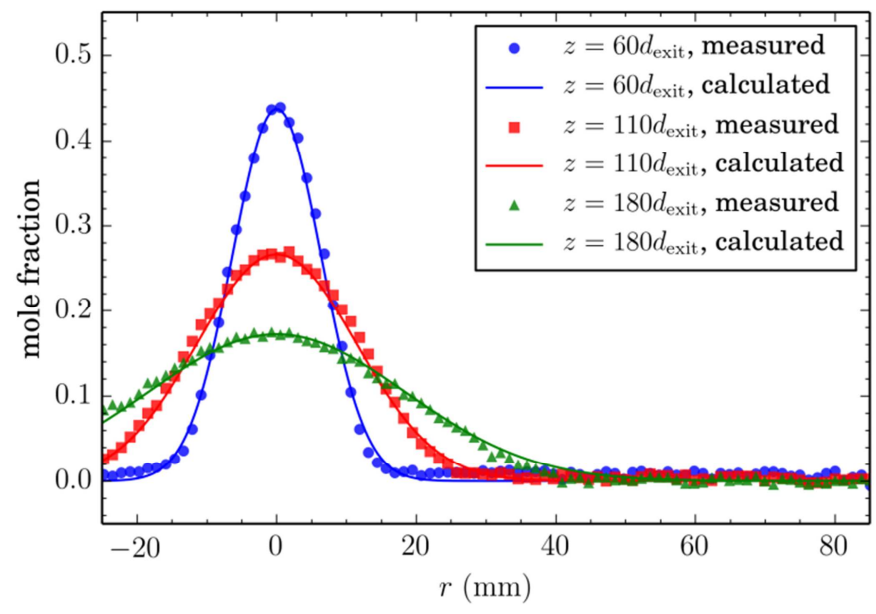

(b) radial mole fraction distributions for $P_{0}=10$ bar

Figure 8 Measured and calculated mean mole fraction distributions for an underexpanded hydrogen jet with $d_{\text {exit }}=1 \mathrm{~mm}\left(\lambda=1.529, \beta_{\mathrm{A}}=0.281, \beta_{\mathrm{S}}=8.632\right.$, and $\left.\beta_{\mathrm{B}}=0.820\right)$.

Figure 9 shows the predicted and measured mean concentration fields for underexpanded jets with a nozzle diameter of $1 \mathrm{~mm}$ for different pressure ratios. The subfigures on the right were obtained from the PLRS photographs, in which a few dark dots were caused by dead pixels in the camera. The model successfully reproduced the concentration field for the whole measurement range. Direct comparisons of different mole fraction profiles including the $4 \% \mathrm{LFL}$ are shown in 
Figure 10 for stagnant pressures up to 60 bar and a nozzle diameter of $1 \mathrm{~mm}$. The model slightly over predicted the LFL at higher pressures, but this over-prediction results in a more conservative estimate of setback distances for safety studies.

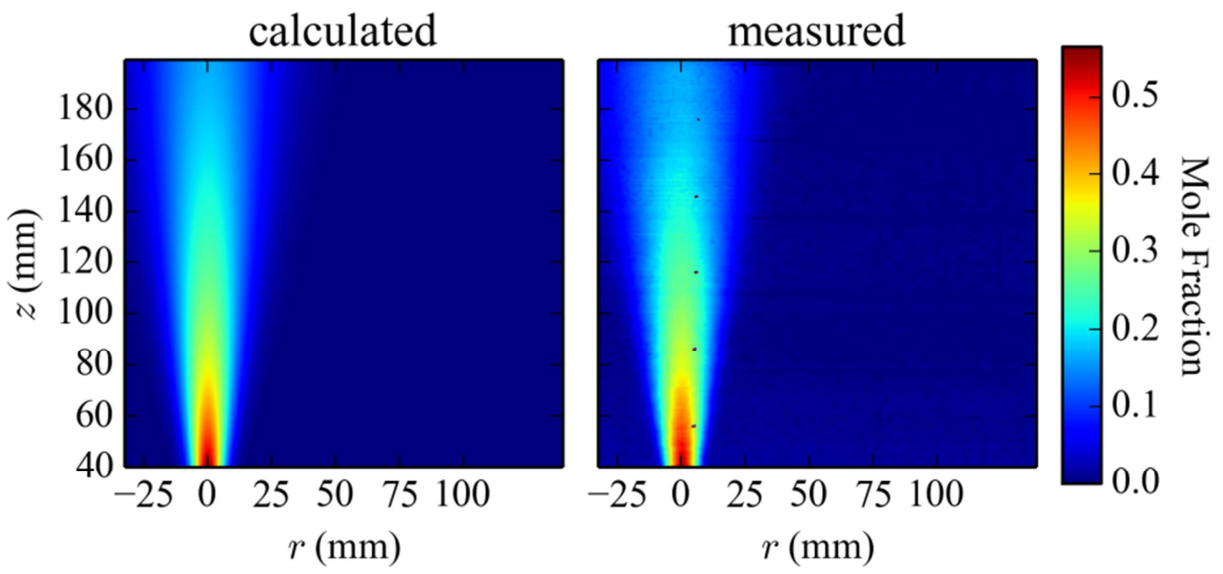

(a) $P_{0}=10$ bar,

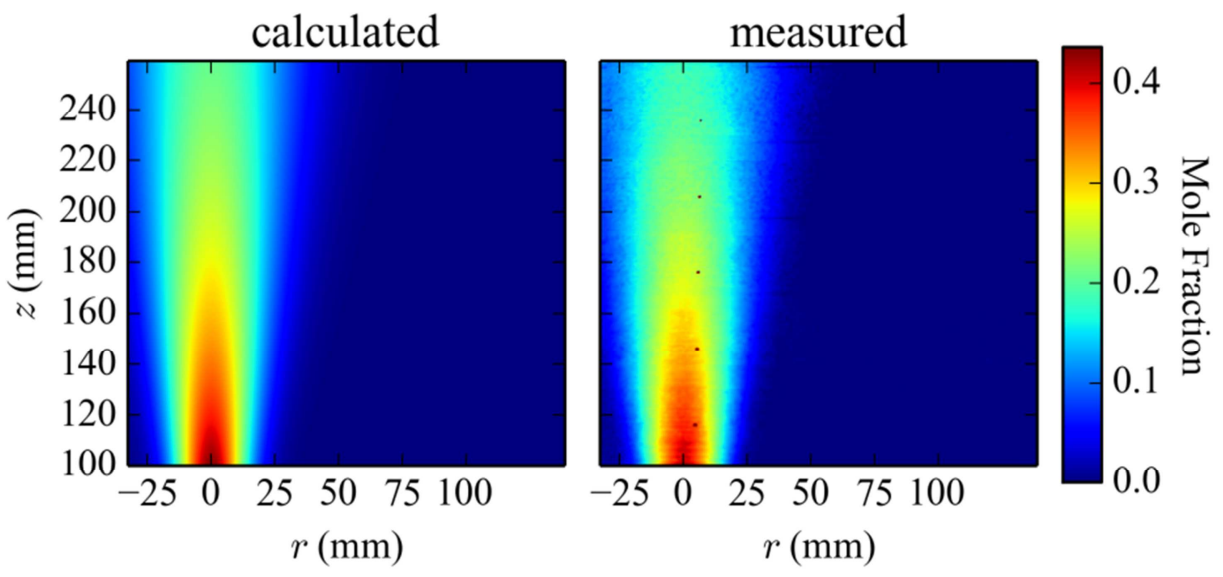

(b) $P_{0}=30$ bar.

Figure 9 Measured and calculated mean mole fraction distributions for the underexpanded hydrogen jets, $d_{\text {exit }}=1 \mathrm{~mm}$.

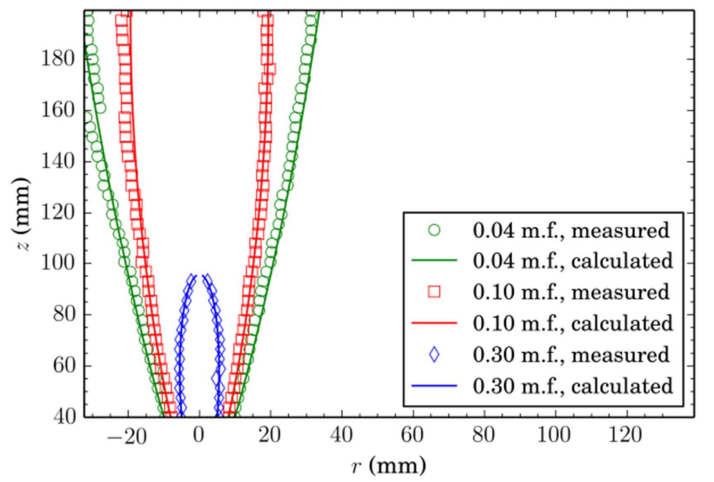

(a) $P_{0}=10$ bar,

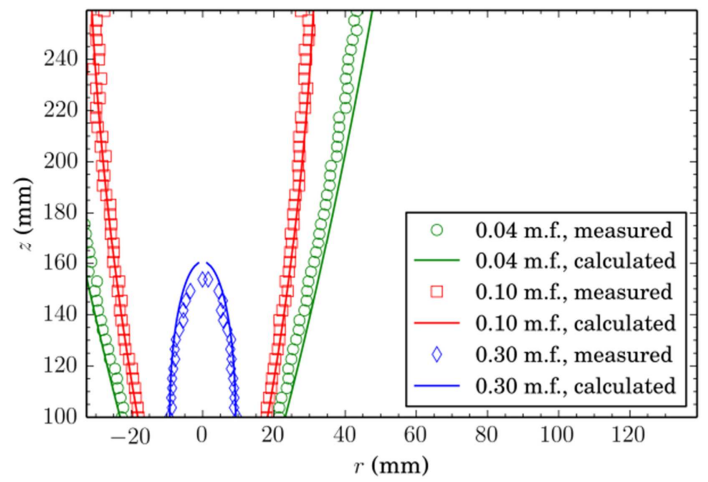

(b) $P_{0}=30$ bar, 


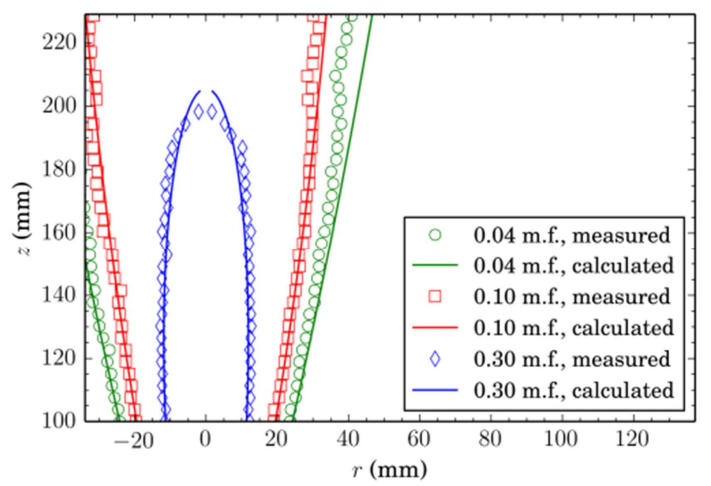

(c) $P_{0}=50$ bar,

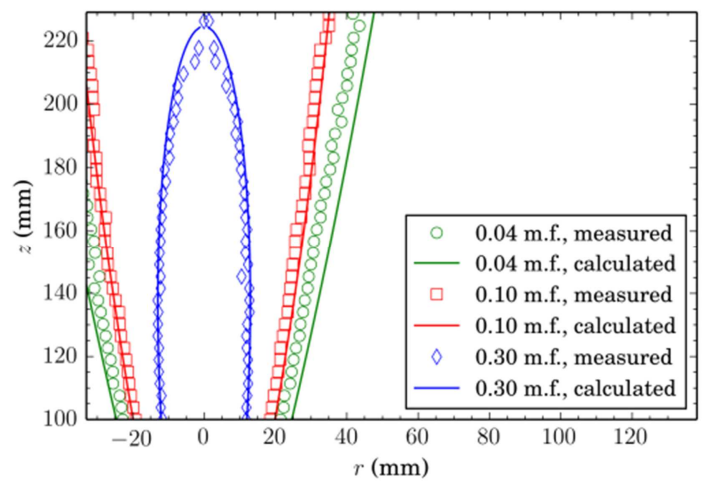

(d) $P_{0}=60$ bar.

Figure 10 Mole fraction profiles (denoted by m.f. in the figure) of underexpanded jets with $d_{\text {exit }}=$ $1 \mathrm{~mm}$.

Predictions using the best-fit parameters obtained from the experimental data in this study are compared with other data to see how accurately the model can predict the centerline concentration decay rate for a wider range of conditions. The model predictions are compared here with two horizontal release experiments. The first experiment used micro katharometers to measure the mole fraction distribution along the jet centerline of a helium jet instead of hydrogen [14]. The helium stagnation pressure was 26 bar and the nozzle exit diameter was 2 $\mathrm{mm}$. The predicted centerline mole fraction distribution agrees well with the measured data as shown in Figure 11. The second experimental study [12], which was carried out outdoors, measured the centerline mole fraction decay of hydrogen jets with much higher stagnation pressures than in the experiments used to find the model parameters, with pressures up to 200 bar. Figure 12 shows the good agreement between the measured and predicted concentrations, especially for the first three data points for each case. Han et al. [12] noted in their paper that the deviations of the measured data far from the exit might be due to wind, which would reduce the measured hydrogen mole fractions. Hence, the slight over-predictions of the mole fractions at large horizontal distance in Figure 12 are not unexpected. Both of these experimental studies used horizontal jets and relatively large distances from the nozzle exit. This is especially true for the second (hydrogen jet) experiment where the furthest probe was $9000 d_{\text {exit }}$ from the nozzle exit. The comparisons indicate that the model gives reasonable predictions for underexpanded jets in both the horizontal and vertical directions even at very large distances. 


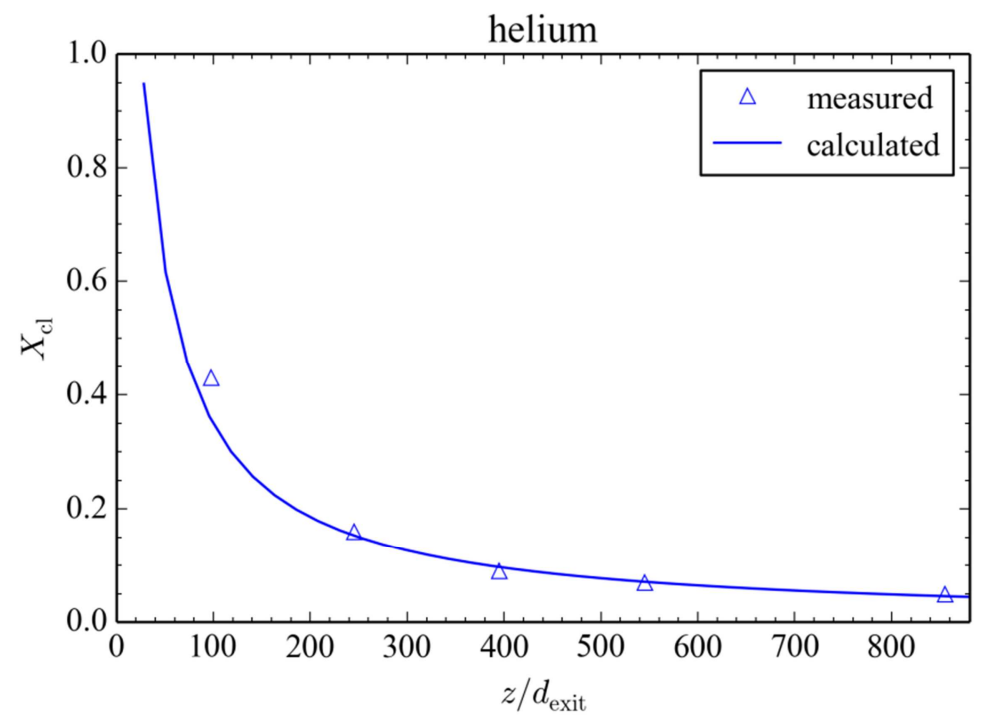

Figure 11 Predicted and measured centerline mole fractions for a horizontal helium jet with a stagnation pressure of 26 bar and $d_{\text {exit }}=2 \mathrm{~mm}$. The measured data is from Christopher et al. [14].

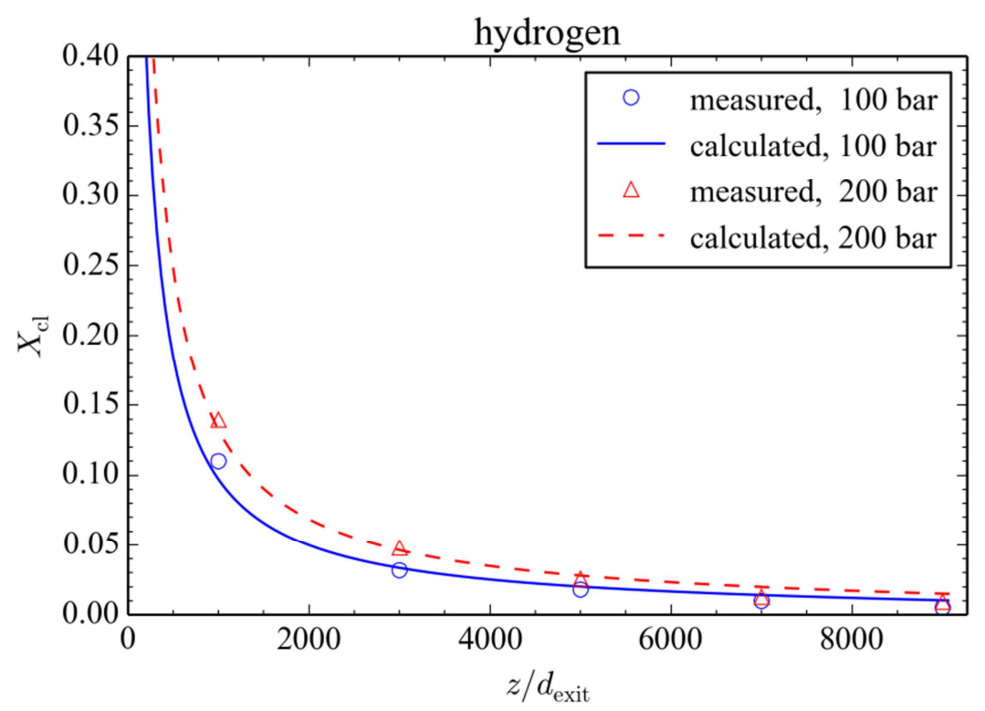

Figure 12 Predicted and measured mole fractions in horizontal hydrogen jets, $d_{\text {exit }}=1 \mathrm{~mm}$. The measurements are from Han et al. [12].

\section{Conclusions}

Concentration profiles were measured in subsonic hydrogen and helium jets and underexpanded supersonic hydrogen jets into air at pressures up to 60 bar and nozzle exit diameters of $0.5 \mathrm{~mm}$ to $1.5 \mathrm{~mm}$. A PLRS system was used to measure the concentration profiles in the jets. The measured concentration distributions were then used to determine improved values for four uncertain parameters in a reduced-order model for subsonic jets and in a combined notional nozzle and reduced-order model for underexpanded jets. The four uncertain parameters were the relative 
concentration to velocity spreading ratio, $\lambda$, an entrainment coefficient, $\beta_{A}$, the model starting point (relative to the release diameter), $\beta_{S}$, and the model initial halfwidth (relative to the release diameter), $\beta_{B}$. The model parameters were found by minimizing the error of the entire measured concentration fields for the subsonic and underexpanded jets, rather than looking only at the centerline concentration decay, as is typically done for model validation. The best fit parameters were determined to be $\lambda=1.510, \beta_{\mathrm{A}}=0.248, \beta_{\mathrm{S}}=0$, and $\beta_{\mathrm{B}}=0.763$ for the subsonic helium and hydrogen jets and $\lambda=1.529, \beta_{\mathrm{A}}=0.281, \beta_{\mathrm{S}}=8.632$, and $\beta_{\mathrm{B}}=0.820$ for the underexpanded hydrogen jets. Using these parameters, the model has much better agreement with the measured radial concentration profiles than historically used model parameters. The results show that the radial spreading of the concentration profile has an important effect on the model predictions that cannot be seen by just comparing the centerline concentration decay rates. These parameters were then used in the notional nozzle/reduced-order model to predict the concentrations in hydrogen jets up to 200 bar with the results agreeing well with data in the literature. The current model is expected to be valid for higher pressures, as the same phenomena occur, however, more experimental data is needed for validation at the high working pressures of the current hydrogen fueling infrastructure (typically 700 bar).

\section{Acknowledgments}

This work was supported by the National Basic Research Program of China ("973” Project) Grant No. 2011CB706904, the National Natural Science Foundation of China, Grant No. 51476091, and by the Science Fund for Creative Research Groups of the National Natural Science Foundation of China, Grant No. 51321002. The authors acknowledge the financial support from China Scholarship Council. This research was also supported by the United States Department of Energy Fuel Cell Technologies Office, under the Safety, Codes, and Standards subprogram element managed by Will James. Sandia National Laboratories is a multi-program laboratory managed and operated by Sandia Corporation, a wholly owned subsidiary of Lockheed Martin Corporation, for the U.S. Department of Energy's National Nuclear Security Administration under contract DE-AC04-94AL85000.

\section{References:}

[1] Molkov V. Fundamentals of Hydrogen Safety Engineering. 2012

[2] Lachance J, Houf W, Middleton B and Fluer L. Analyses to Support Development of Risk-Informed Separation Distances for Hydrogen Codes and Standards. SAND2009-0874.Sandia National Laboratories, 2009

[3] Inman JA, Danehy PM, Nowak RJ and Alderfer DW. Fluorescence imaging study of impinging underexpanded jets. 2008:2008-619

[4] Houf W and Schefer R. Analytical and experimental investigation of small-scale unintended releases of hydrogen. International Journal of Hydrogen Energy, 2008, 33(4):1435-1444

[5] Schefer RW, Houf WG and Williams TC. Investigation of small-scale unintended releases of hydrogen: Buoyancy effects. International Journal of Hydrogen Energy, 2008, 33(17):4702-4712

[6] Schefer R, Houf W and Williams T. Investigation of small-scale unintended releases of hydrogen: 
momentum-dominated regime. International Journal of Hydrogen Energy, 2008, 33(21):6373-6384

[7] Papanicolaou PN and List EJ. Investigations of round vertical turbulent buoyant jets. Journal of Fluid Mechanics, 1988, 195:341-391

[8] Veser A, Kuznetsov M, Fast G, Friedrich A, Kotchourko N, Stern G, Schwall M and Breitung W. The structure and flame propagation regimes in turbulent hydrogen jets. International Journal of Hydrogen Energy, 2011, 36(3):2351-2359

[9] Rodi W. Turbulent buoyant jets and plumes.Pergamon press New York, 1982

[10] Chen CJ and Rodi W. Vertical turbulent buoyant jets: a review of experimental data. Nasa Sti/Recon Technical Report a, 1980, 80:23073

[11] Ruggles AJ and Ekoto IW. Ignitability and mixing of underexpanded hydrogen jets. International Journal of Hydrogen Energy, 2012, 37(22):17549-17560

[12] Han SH, Chang D and Kim JS. Experimental investigation of highly pressurized hydrogen release through a small hole. International Journal of Hydrogen Energy, 2014, 39(17):9552-9561

[13] Pitts WM. Effects of global density ratio on the centerline mixing behavior of axisymmetric turbulent jets. Experiments in Fluids, 1991, 11-11(2-3)

[14] Li X, Christopher DM, Hecht E and Ekoto IW. Comparison of two-layer model for high pressure hydrogen jets with notional nozzle model predictions and experimental data: International Conference on Hydrogen Safety, Yokohama, Japan, 2015

[15] Gebhart B, Hilder DS and Kelleher M. The Diffusion of Turbulent Buoyant Jets. Advances in Heat Transfer, 1984:1-57

[16] El-Amin MF and Kanayama H. Similarity consideration of the buoyant jet resulting from hydrogen leakage. International Journal of Hydrogen Energy, 2009, 34(14):5803-5809

[17] Winters WS. Modeling Leaks from Liquid Hydrogen Storage Systems. Livermore, CA: Sandia National Laboratories, 2009

[18] Xiao J, Travis JR and Breitung W. Non-Boussinesq Integral Model for Horizontal Turbulent Buoyant Round Jets. Science and Technology of Nuclear Installations, 2009:1-7

[19] Bonelli F, Viggiano A and Magi V. A Numerical Analysis of Hydrogen Underexpanded Jets Under Real Gas Assumption. Journal of Fluids Engineeringjournal of Fluids Engineering, 2013, 135(12): 121101

[20] Hourri A, Angers B, Bénard P, Tchouvelev A and Agranat V. Numerical investigation of the flammable extent of semi-confined hydrogen and methane jets. International Journal of Hydrogen Energy, 2011, 36(3):2567-2572

[21] Xu BP, Zhang JP, Wen JX, Dembele S and Karwatzki J. Numerical study of a highly under-expanded hydrogen jet: 1st International Conference on Hydrogen Safety, Pisa, 2005

[22] Velikorodny A and Kudriakov S. Numerical study of the near-field of highly underexpanded turbulent gas jets. International Journal of Hydrogen Energy, 2012, 37(22):17390-17399

[23] Han SH, Chang D and Kim JS. Release characteristics of highly pressurized hydrogen through a small hole. International Journal of Hydrogen Energy, 2013, 38(8):3503-3512

[24] Houf WG and Winters WS. Simulation of high-pressure liquid hydrogen releases. International Journal of Hydrogen Energy, 2013, 38(19):8092-8099

[25] Xiao J, Travis JR and Breitung W. Hydrogen release from a high pressure gaseous hydrogen reservoir in case of a small leak. International Journal of Hydrogen Energy, 2011, 36(3):2545-2554

[26] Williams TC and Shaddix CR. Simultaneous correction of flat field and nonlinearity response of intensified charge-coupled devices. Review of Scientific Instruments, 2007, 78(12):123702 
[27] Hecht E, Li X and Ekoto IW. Validated Equivalent Source Model for an Under-expanded Hydrogen Jet: International Conference on Hydrogen Safety, Yokohama, Japan, 2015

[28] Birch AD, Brown DR, Dodson MG and Swaffield F. The structure and concentration decay of high pressure jets of natural gas. Combustion Science and Technology, 1984, 36(5-6):249-261

[29] Richards CD and Pitts WM. Global density effects on the self-preservation behaviour of turbulent free jets. Journal of Fluid Mechanics, 1993, 254:417-435

[30] Veser A, Kuznetsov M, Fast G, Friedrich A, Kotchourko N, Stern G, Schwall M and Breitung W. The structure and flame propagation regimes in turbulent hydrogen jets. International Journal of Hydrogen Energy, 2011, 36(3):2351-2359

[31] Abraham G. Horizontal jets in stagnant fluid of other density. Journal of the Hydraulics Division, 1965, 91(4):139-154

[32] Hirst EA. Analysis of Buoyant Jets within the Zone of Flow Establishment. US Atomic Energy Commission, Oak Ridge Nat. Lab., Rep. N. Ornl-Tm-3470. Oak Ridge, Tennessee. Prediction of Initial Mixing for Municipal Ocean Discharges, 1971

[33] Ball CG, Fellouah H and Pollard A. The flow field in turbulent round free jets. Progress in Aerospace Sciences, 2012, 50:1-26

[34] Hussein HJ, Capp SP and George WK. Velocity measurements in a high-Reynolds-number, momentum-conserving, axisymmetric, turbulent jet. Journal of Fluid Mechanics, 1994, 258(1):31 75

[35] Malmstr M TG, Kirkpatrick AT, Christensen B and Knappmiller KD. Centreline velocity decay measurements in low-velocity axisymmetric jets. Journal of Fluid Mechanics, 1997, 346:363 - 377

[36] Fukushima C, Aanen L and Westerweel J. Investigation of the Mixing Process in an Axisymmetric Turbulent Jet Using PIV and LIF. Laser Techniques for Fluid Mechanics, 2002:1-11

[37] Bell IH, Wronski J, Quoilin S and Lemort V. Pure and Pseudo-pure Fluid Thermophysical Property Evaluation and the Open-Source Thermophysical Property Library CoolProp. Industrial \& Engineering Chemistry Research, 2014, 53(6):2498-2508

[38] Birch AD, Hughes DJ and Swaffield F. Velocity decay of high pressure jets. Combustion Science and Technology, 1987, 52(1-3):161-171

[39] Storn R and Price K. Differential Evolution - A Simple and Efficient Heuristic for Global Optimization over Continuous Spaces. Journal of Global Optimization, 1997(11):341-359

[40] Wales DJ and Doye JPK. Global Optimization by Basin-Hopping and the Lowest Energy Structures of Lennard-Jones Clusters Containing up to 110 Atoms. The Journal of Physical Chemistry a, 1998, 101(28):5111 - 5116 